\title{
La ópera en Alemania ¿una «quijotada»? La figura de Don Quijote en la crítica operística alemana de la ilustración.
}

\author{
Cristina URChUeguía*
}

Quiero excluir a Don Quijote y sus molinos de viento: porque disfrutan siempre de su propia libertad aventurera.

Johann Mattheson, $1744^{1}$

En 1745 Johann Adolph Scheibe describe en los siguientes términos la situación de la ópera en Alemania:

Si bien los dei ex machina y los encantamientos han ido sucumbiendo en gran medida y se ha empezado a reconocer lo deleznable que es dejarse llevar no por historias naturales sino imposibles y en lugar de las verdaderas preferir las quimeras y las ensoñaciones quijotescas y llevarlas al escenario, en el que no sólo se deben alimentar los sentidos sino enseñar y formar, aun así han permanecido en las transformaciones del escenario diversas cosas antinaturales. ${ }^{2}$

*. Musikwissenschaftliches Institut. Universität Zürich

1. Mattheson, Johann, Die neueste Untersuchung der Singspiele, Hamburgo, s.n., 1744, p. 93: «Don Quixotte und seine Windmühlen will ich ausnehmen: denn die haben jederzeit ihre abentheuerlich Freyheit.»

2. SCHEIBE, Johann Adolph, Critischer Musicus, publicación periódica 1737-1740. Neue vermehrte und verbesserte Auflage, Leipzig, 1745, edición facsimilar, Hildesheim, Olms, 1970, capítulo 23, pp. 224s.: «Die Maschinengötter und die Zaubereyen haben anitzo zwar meistentheils ihren Untergang gelitten und man hat angefangen, einzusehen, wie abgeschmackt es ist, von dem 
Esta cita ha sido tomada de la segunda edición aumentada de Critischer Musikus, el primer compendio crítico sobre música publicado en Alemania. La frase, lejos de ser una apreciación abstracta, tiene un trasfondo histórico real.

En 1750, cinco años tras la publicación del texto de Scheibe, sale a subasta pública el edificio de la Oper am Gänsemarkt, la ópera en el mercado de los gansos de Hamburgo tras la quiebra de la empresa en 1738. La cita de Scheibe alude implícitamente al declive de esta casa, inminente ya en los años cuarenta del siglo XVIII. Hamburgo es, junto al escenario en Dresden, el punto de partida de la ópera en suelo alemán. Uno, por otra parte, muy frecuentado por el caballero de la triste figura: en 1690 se estrena Der irrende Don Quixotte de la Mancia (El errante Don Quijote de la Mancha) de Johann Philipp Förtsch, entre 1722 y 1737 se representa Don Quixote in Sierra Morena (Don Quijote en Sierra Morena) de Francesco Bartolomeo Conti durante 9 temporadas en versión semiadaptada: las arias en italiano, el texto hablado en alemán. En 1727 Georg Philipp Telemann estrena Sancio oder die siegende Großmuth (Sancio o la clemencia victoriosa) que se representará durante 9 temporadas hasta $1737 .^{3}$

El fracaso de la ópera de Hamburgo tras 72 años de funcionamiento no se puede explicar de forma monocausal. Y no es tampoco mi intención analizar los motivos de la quiebra. Quiero en cambio profundizar en las razones que llevaron a que Johann Adolph Scheibe, autor de uno de los primeros y más relevantes textos sobre la ciencia musical de la ilustración germánica, se valiese precisamente de la figura de Don Quijote para criticar el género operístico. El escenario de Hamburgo tenía un imponente elenco de protagonistas que ofrecer, todos ellos irreales, todos ellos fantásticos: personajes míticos como Semele, Dido, Aeneas, Andromeda, Ariadna, Hércules o Theseo, históricos, como Xerxes, Aníbal, Atila, Vespasiano, Genserico, Nabucodonosor o Julio César, novelescos como Rolando, Mustapha y bíblicos desde Caín y Abel hasta Jesucristo, y todos actúan en argumentos que se valen de cualquier medio, por rocambolesco que sea, para dejar al público boquiabierto. Don Quijote no es pues el único al que cabe reprocharle lo que Scheibe denomina «historias imposibles, quimeras y ensoñaciones». Sin lugar a dudas todos estos personajes con sus historias podrían haber suscitado las iras de Scheibe de igual manera. ¿Cómo llega la figura de Don Quijote a adquirir valor paradigmático en este contexto? ¿Es que acaso bajó él mismo del escenario hamburgués para ofrecer sus servicios cual agente doble a los críticos de la ópera?

natürlichen auf unmögliche, und von den wirklichen Handlungen auf verkehrte Träumereyen, und Don Quischottenmäßige Schwärmereyen zu fallen, und sie auf der Schaubühne, die nicht allein die Sinne einnehmen, sondern die uns auch unterrichten und lehren soll, vorzustellen. Es ist uns aber in den Veränderungen der Bühne noch unterschiedliches Unnatürliches geblieben.» La primera edición apareción en Hamburgo, 1738.

3. MARX, Hans-Joachim y SCHRÖDER, Dorothea, Die Hamburger Gänsemarkt-Oper. Katalog der Textbücher (1678 - 1748), Laaber, Laaber, 1995. 
Para entender este fenómeno es necesario reconstruir la panorámica intelectual en cuyo seno surge el texto de Scheibe de forma global. La crítica a la ópera, tal y como es articulada por Scheibe, forma parte de una ofensiva estético-filosófica mucho más amplia, en la que la ópera tuvo el discutible privilegio de convertirse en cabeza de turco: por ser nueva, por ser comercial, extravagante, exhibicionista y espectacular, por ser un género que, al menos en Hamburgo, abría sus puertas a todos los estratos sociales, dependiendo por ello tanto de la tolerancia de los superiores como de la afición y la disposición de la población a comprar entradas en lugar de limitarse a servir de espejo de virtudes nobiliario o de carnaza para satisfacer el insaciable apetito de transcendencia estética o entretenimiento de la aristocracia.

Si observamos la primera época de la ópera en Alemania, desde 1627 con el solitario Dafne de Heinrich Schütz o desde 1644 si nos atenemos a la primera ópera alemana cuya música se ha conservado, Seelewig de Theophil Staden, veremos que la oposición al género es expresada únicamente desde el púlpito y se nutre exclusivamente de argumentos teológicos. Desde el punto de vista eclesiástico y antes de la apertura de la ópera de Hamburgo el problema es serio sin llegar a ser preocupante dado que el objeto de crítica se manifiesta sólo de forma ocasional y en espacios sociales tan reducidos como impermeables. La ópera de Hamburgo conlleva una radicalización de las posiciones por haber democratizado el género, convirtiéndolo en espectáculo frecuente, accesible a amplios círculos sociales. Y tanto más como que no es susceptible a ser erradicado limpiamente sin perjuicio del resto de espectáculos y géneros teatrales. Elementos y formas de expresión operísticos coexisten y cohabitan con todo tipo de estrategias escénicas en un ambiente que vive precisamente del intercambio entre géneros cuyos límites son difusos: comedia, tragedia, Lustspiel, Trauerspiel, burlesca, Singspiel, opereta, opéra comique, opera seria, opera buffa, Tragedie Lyrique, Intermezzo, pantomima, Vaudeville, arlequinada, pasticcio, ballet, teatro de marionetas o incluso espectáculos de carácter circense se concatenan y se mezclan sin solución de continuidad y los elementos propios de la ópera son usados indiscriminadamente en todos ellos ya sea incluyendo Ariette, cancioncillas o música incidental en las obras del teatro hablado, realizando primeros experimentos con el melodrama o integrando técnicas del teatro improvisado, Stegreiftheater, en las óperas. Abrir las puertas de la ópera de Hamburgo en 1678 con una ópera de argumento bíblico, Der erschaffene, gefallene und auffgerichtete Mensch (La creación, perdición y elevación del hombre) de Johann Theile, una historia que condensa en formato alegórico-operístico desde la génesis hasta el juicio final, quizá obedeciese al deseo o la necesidad de suavizar profilácticamente el conflicto o en su defecto de establecer una base de conciliación. De ser así no obtuvo en principio el resultado que se esperaba.

El pastor protestante Anton Reiser, uno de los más acérrimos oponentes a la ópera, no se deja engatusar, en 1682 escribe refiriéndose a las obras representadas en el escenario de Hamburgo: 
$\mathrm{O}$, se apagase ese río de fuego infernal que arde sólo por el primitivo placer y el deseo, ese horno de Venus, aventado por el pecado original babélico, prendido por gente que por regla general se tiene por aventajada. Atenta contra la conciencia quien denomina en el título sus tórridos panfletos una defensa de las óperas cristianas, siendo como es conocido e irrefutable que tuvieron su origen y principio en el paganismo anticristiano e idólatra y que fueron rechazadas y maldichas por aquellos de entre los paganos entendidos en la pura luz de la naturaleza por fastidiosas y deshonestas. ${ }^{4}$

Esta invectiva contra la ópera refleja en su variante más populista la línea de argumentación dominante en la iglesia protestante alemana, al menos en su frente más ortodoxo, el movimiento pietista que a finales de los años 70 del siglo XVII dominaba en la ciudad de Hamburgo. La ópera es criticada sin pormenorizar ni en su estructura ni en su presencia estética, se alude a ella únicamente como antro de perdición, poblado por dioses paganos, en que las historias no sólo son contrarias a la moral cristiana y al puritanismo protestante sino que constituyen una abierta incitación a la idolatría. El texto de Reiser culmina en una cita de Santo Tomás de Aquino «est ibi peccatum mortale, cui soli debetur Luctus perpetus», a quien represente o visite la ópera le esperan ni más ni menos que las llamas del infierno. Esta amenaza no es más que la repetición radicalizada de la posición del pietismo protestante con respecto al teatro en general. Y que la ópera careciese de la protección de una tradición histórica legitimadora que la poetología pro-aristólelica del clasicismo había provisto para el teatro y se decantase desde un principio por historias mitológicas, heroicas y novelescas no supuso precisamente una ventaja.

La relevancia social y cultural de este tipo de ataques no se debe subestimar dado que se articulan en foros de discusión públicos y se distribuyen con panfletos impresos, Flugblätter, de amplia difusión entre los círculos interesados. No cayeron tampoco en saco roto. La ópera de Hamburgo intentó un contraataque utilizando las armas de la propia iglesia. En 1682, para neutralizar al clero vociferante, el empresario de Hamburgo Johann Adam Reinicke encarga dos informes teológicos y jurídicos a las facultades de teología y derecho de Wittenberg y Rostock. El informe de la Universidad de Wittenberg

4. REISER, Anton, 1682, en: Quellentexte zur Konzeption der europäischen Oper im 17. Jahrhundert, ed. Heinz Becker, Kassel et al., Bärenreiter, 1981, pp. 171-173: «O dass dieser höllische von schnöder Lust und Geilheit immer brennende Feuerfluss und mit der Bluthschand angefeuerte Babelische Venus-Ofen, von denen angezündet, welche man ins gemein von klugen Leuthe zu halten pfleget, endlich einmahl wiederumg möchte gelöschet werden! [...] [S. 64] Gewissenlos handelt er, wenn er auf dem Titul seine Schand Charteken nennet eine Verteidigung der Christlichen Operen, da doch bekannt und nicht geleugnet werden kann, dass solche aus dem ohnchristlichen und abgöttischen Heidenthumb ihren Ursprung und Anfang herbekommen. und von denen aus dem blossen Liecht der Natur Verständigen unter den Heiden selbst als ärgerlich, ohnehrlich und dem gemeinen Wesen schändlich verworffen und verdammet worden.»

Véase en este contexto: DöHRING, Sieghart, «Theologische Kontroversen um die Hamburger Oper», Festschrift Klaus Hortschansky zum 60. Geburtstag, ed. Axel Beer y Laurenz Lütteken, Tutzing, Hans Schneider, 1995, pp. 111-123. LE BAR, Ann Catherine, Musical Culture and the Origins of the Enlightement in Hamburg. PhD Diss. University of Washington 1993, pp. 63ss. 
fue publicado 5 años más tarde, en 1687. Éste, más ponderado, otorga que no es la ópera in toto la que es repudiable, sino sólo aquellas manifestaciones del género que no se atienen a las bases de la fe. No es un pecado representar o consumir óperas: «propter defectum interdicti. Puesto que ningún lugar del texto de la biblia lo prohibe.» ${ }^{5}$

Una batalla ganada, pero sólo la primera, a la que seguirá una segunda batalla tanto más encarnizada cuanto más se adentran en el terreno estructural y estético del nuevo género. Mientras el público alemán es testigo en los años 80 del siglo XVII, a ratos preocupado, a ratos divertido, de la exhibición pública de tremebundos escrúpulos religiosos y a las cada vez más frecuentes representaciones de ópera, en Londres Charles de Saint-Evremond forja las armas para la segunda ofensiva de los opositores a la ópera, esta vez dotada del arsenal argumentativo elaborado por el racionalismo ilustrado inglés, francés y alemán.

Charles de Saint-Evremond (1616-1703) no es un desconocido para los estudiosos de Don Quijote, y su importancia reside en haber sido partícipe en la famosa Querelle des Ancienne et de Modernes, cuyos representantes más prominentes fueron Nicolas Boileau como partidario de los antiguos y Charles Perrault en el bando de los modernos. Saint-Evremond se une a este último e incluye la novela Don Quijote entre las obras de referencia necesarias junto con «clásicos» de Torquato Tasso o Michel de Montaigne, los textos canónicos para adquirir buen gusto en todos los asuntos. ${ }^{6}$ En su exilio londinense dedica su tiempo entre 1663 y 1703 a la literatura, a la historia literaria, al trabajo intelectual que transmite tanto en salones y a través de relaciones epistolares como de forma individual escribiendo, pero también se dedica con gran ahínco activamente a la música. El salón de Madame de Mazarin hace las veces de catalizador: es lugar de encuentro para las tertulias de intelectuales, escenario para la publicación de textos, música, teatro y caldo de cultivo para el intercambio de ideas. ${ }^{7}$ La ópera es uno de los temas que más interesa a los aristócratas ingleses por ser un género nuevo que conocen ante todo indirectamente, a través de narraciones de viajeros o de las descripciones de los $m a$ gazines. Y no sólo interesa la ópera en su punto de origen, Italia, sino igualmente en el país vecino, Francia. La corte francesa había entronizado ya a principios de los años 70 del siglo XVII al tandem formado por el compositor Jean Baptiste Lully y el autor dramático Philippe Quinault, quienes entre 1673 y 1687 suministran a la corte regularmente con música escénica de todo tipo:

5. Theologische und Juristische Fakultät der Universität Wittenberg. Gutachten über die Opern. en: Quellentexte (véase nota 4), pp. 180ss.

6. Véase por ejemplo el tratado: Saint-Evremond, Charles de, Sur la tragédie ancienne et moderne, Londres, 1677.

7. Fuentes sobre la relación de Saint-Evremond y Madame de Mazarin en: Schriften und Briefe des Herrn von Saint Evremond und die Memoiren der Herzogin von Mazarin, ed. Karl Federn, Múnich, Georg Müller, 1912; Saint-Evremond : a voice from exile : newly discovered letters to Madame de Gouville and the Abbé de Hautefeuille, (1697-1701), ed. Denys Potts, Oxford, Legenda, 2002. 
ballets, idilios, pastorales, mascaradas, comedias y cada año, como plato fuerte, una Tragedie Lyrique, el género más noble. ${ }^{8}$

Charles de Saint-Evremond, soldado y galant-homme se convierte en el consejero y testigo de excepción para el círculo de nobles que frecuentan el salón de su amiga Madame de Mazarin. La fama que le precede es la de «un homme du monde qui a le goust le plus fin sur toutes ces choses», universalista y paradigma del buen gusto. ${ }^{9}$ Aproximadamente en 1678, unos años tras la representación londinense de la ópera Pomone de Cambert, Saint-Evremond plasma en una dilatada epístola a George Villiers, Duque de Buckingham, su opinión sobre la ópera:

Comenzaré siendo franco, admitiendo que no soy un gran admirador de las comedias musicales [...] Mi alma inteligente, más con el espíritu que con los sentidos, se resiste a las impresiones que de ellas recibe, o al menos se abstiene de darles su consentimiento aquiescente, sin el que ningún objeto, incluso el más voluptuoso, puede serme placentero. Una majadería llena de música, danza, decorados y máquinas es una majadería magnífica pero no deja de ser siempre una majadería. ${ }^{10}$

Una manifestación de desagrado tan inequívoca sorprende en un hombre conocido como melómano sincero y amante del teatro. Saint-Evremond fundamenta su juicio negativo con argumentos quirúrgicamente precisos y devastadores que se sucedan como flechas de indios: Los instrumentos hacen un ruido ensordecedor, los recitativos son aburridos, el hecho de que se cante todo el texto es ridículo y contra natura. Si bien es plausible y tiene una legitimación histórica y natural que se canten oraciones, rituales o encantamientos nadie le pediría al carnicero la carne cantando, o mataría a alguien melodiosamente. El único estilo de cantar aceptable es el francés. La expresión de los sentimientos es exasperantemente exagerada. Tampoco los argumentos tienen nada que ver con la realidad, carecen de «vraisemblance», similitud con la naturaleza. El abuso de las máquinas, aunque ya fueran utilizadas excepcionalmente y con buen criterio por los antiguos, es una muestra de mal gusto, esto

8. SCHNEIDER, Herbert, Chronologisch-thematisches Verzeichnis sämtlicher Werke von JeanBaptiste Lully, Tutzing, Hans Schneider, 1981, (Mainzer Studien zur Musikwissenschaft, vol. 14). Schmidt, Carl B., The livrets of Jean-Baptiste Lully's tragédies lyriques: a catalogue raisonné, New York, Performers' Ed, 1995.

9. Jean Donneau de Visé, Prólogo a carta al Duque de Buckingham, publicada en París en febrero de 1683 en Mercure Galante, revista mensual de información cultural fundada por Jean Donneau de Visé en 1672. Véase: Nestola, Barbara, «La musica italiana nel 〈Mercure galant〉(1677-1683)», Recercare, 14, 2002, pp. 139-148.

10. Ibidem, p. 139: «Je comenenceray par un grande franchise, en vous disant que je n'admire par fort les comédies en musique [...] Mon ame d'intelligence avec mon esprit, plus qu'avec mes sens, forme une résistance sur elle aux impressions qu'elle peut recevoir,ou pour le moins, elle manque d'y prester un consentement agréable, sans lequel les objets les plus voluptueux mesme, ne sçauroient me donner un gran plaisir. Une sotise chargée de musique, de dances, de décorations, de machines, est un sotise magnifique, mais toujours sotise.» Véase en este contexto: LowENS, Irwing, «St. Evremond, Dryden, and the Theory of Opera», Criticism, 1, 1959, pp. 226-248. 
es, de un gusto primitivo y plebeyo. Esta última es quizá la acusación más poderosa contra la ópera en el contexto de una estética dominada por el «buen gusto» como quintaesencia del perfeccionamiento de toda persona erudita y sensible.

Si quiere saber lo que es una ópera yo le diré que es una mezcolanza de poesía y música en la que el poeta y el músico, obstaculizados por igual el uno por el otro, se aplican con tesón en conseguir un resultado deplorable. ${ }^{11}$

La única esperanza que le queda al espectador de una ópera es la certeza de que el espectáculo que se le está ofreciendo tiene un final. No obstante, la ambivalencia que se percibe en la conclusión que Saint-Evremond da a su texto, revela que algo tiene que tener la ópera para que merezca tan intensa atención: «la concepción de las óperas no podría ser más defectuosa, pero he de reconocer al mismo tiempo que nadie es capaz de trabajar tan bien sobre un objeto tan mal concebido que Baptiste [Lully], y nadie es capaz de cumplir aquello que le exigen mejor que Quinaut.» ${ }^{12}$

Saint-Evremond no se limitó a expresar sus ideas sobre la ópera en forma discursiva sino que las utilizó como inspiración para una comedia. Les Opéras, escrita aprox. en 1676, tenía como objeto servir de entretenimiento en una velada de su amiga Madame de Mazarin. ${ }^{13}$ Valiéndose del estilo parodístico, al que ya recurrió para mofarse de los políticos en Sir Politick would-be (1662-1665) o del amaneramiento de los hombres de letras en Comedie des académistes (1650), construye una divertida comedia en que incluye la lista completa de denuestos contra la ópera desarrollada en la carta al Duque de Buckingham. ${ }^{14}$

En la comedia Les Opéras encontramos a Don Quijote reencarnado en un alter ego femenino, la joven Crisotine, que ha enloquecido debido al consumo indiscriminado de óperas. Algunos de los síntomas de su enfermedad mental son análogos a los de Alonso Quijano: ha perdido el contacto con la realidad e intenta relacionarse con ella imitando lo que ha observado en las óperas, esto es, cantando donde los demás hablan, reproduciendo exclusiva-

11. Mercure Galante (véase nota 9), p. 141: «Si vous voulez sçavoir c'est qu'un opéra, je vous dirai que q'est un travail bigèarre de poësie et musique, où le poëte et le musicien, égalemente gesnez l'un par l'autre, se donnen bien de la peine à faire un méchant ouvrage.»

12. Ibidem, p. 144: «la constitucion de nos opéras ne sçaurait guère estre plus défectueuse; mais il faut avoüer en mesme temps que personne ne travaillera jamais si bien que Baptiste sur un sujet mal conceu, et qu'il n'est pas aisé de faire mieux que Quinaut, en ce qu'on exige de luy.» Véase con respecto a la recepción e la obra de Lully por Saint-Evremond: Textes sur Lully et l'opera français, Charles Perrault, Charles de Saint-Evremond, A.L. Le Brun, Reproducción de las ediciones: Paris 1674, 1684 y 1712, ed. François Lesure, Ginebra, Minkoff, 1987.

13. Les Opéras fue publicada de forma póstuma en: SAINT-EvremENod, Charles de, Euvres Meslées, vol. 2, Londres, 1705, edicion facsimilar comentada, ed. Robert Finch y Eugène Joliat, Ginebra, Droz, 1979. (Textes Littéraires Français).

14. Sir politick would-be fue escrita entre $1662-1665$ y toma a su personaje principal de la comedia Volpone de Ben Johnson (1606). 
mente citas de la tragedie lyrique Cadmus et Hermione, la primera tragedia musical de J. B. Lully estrenada en 1673. Con su amado Tirsolet se comunica intercambiando citas de la ópera y ambos se identifican con la obra hasta el punto de adoptar en sus convesaciones los nombres de los personajes. En su discurso amatorio reproducen los afectos de la obra de Lully: el amor desmesurado, la tristeza extrema ante la despedida, la deseperación, el desconsuelo ante cualquier contrariedad o la alegría sin límites por nimiedades, algo que sus parientes observan con incomprensión, desagrado y preocupación crecientes. No hay duda de que el caso precisa atención profesional. El médico consultado a tal efecto, Mr. Guillaut, cree reconocer a la primera el desencadenante de este cuadro patológico: «¿No es acaso una locura sobrevenida por la lectura de novelas? Las novelas suelen embrollar con frecuencia el espíritu de los jóvenes.» ${ }^{15}$ Esta reacción es un eco de los debates que desde la aparición de las primeras novelas modernas, entre ellas el Quijote, suscitó el género novelístico durante todo el siglo XVII. En el debate entre partidarios y detractores de la novela, sospechosa por su tendencia a la quimera y al desvarío, Don Quijote desempeña obviamente y por derecho propio un papel paradigmático, por ser a la vez una novela y una mise en abîme, una novela que habla precisamente de los efectos que la novela puede tener en la imaginación. ${ }^{16}$

El médico no es el único que parece ser consciente de los peligros que acechan en las lecturas inadecuadas. El padre de Crisotine ya manifiesta su preocupación en el primer acto: «¿No es acaso este jóven [Tirsolet] quien le hizo leer L'Astrées y no le hablaba más que de la orilla del Lignon? Esto es peligroso para los espíritus jóvenes [...] Yo ya temía que le metería en la cabeza la fantasía de hacerse pastora, y se la llevaría un buen día al pais de Fôrets.» ${ }^{17}$

Mr. Crisard reproduce casi textualmente las palabras de la sobrina de Alonso Quijano con respecto a la novela Pastoral Diana de Montemayor en el $6^{\circ}$ capítulo de la novela de Cervantes:

-¡Ay señor! - dijo la Sobrina -. Bien los puede vuestra merced mandar quemar, como a los demás; porque no sería mucho que, habiendo sanado mi señor tío de la enfermedad caballeresca, leyendo éstos se le antojase de

15. Les Opèras (véase nota 13), p. 59: «Mr. Guillaut: N'est-ce point quelque Folie qui lui foit venuë de la Lecture des Romans? Les Romans gâtent assez souvent l'Esprit des jeunes personnes.»

16. Véase en este contexto: PARADA, Arturo, «La recepción del Quijote en los siglos XVII y XVIII en tierras Alemanas, ¿〈bien〉o 〈herramienta〉?» Anales Cervantinos, 36, 2004, pp. 345-356.

17. Les Opèras (véase nota 13), p. 42: «Mr. Crisard: N'est pas ce Jeune homme qui lui faisot lire les Astrées, \& ne l'entretenoit jamais que de la Riviere de Lignon? Cela est dangereux pour les jeunes Esprits; [...] Je craignois qu'il ne lui mit dans la tête la fantaisie d'étre Bergere; \& qu'il ne la menât un beau jour au Pays de Fôrets.» L'Astrées, Novela Pastoral utópica de Honore d'Urfé, publicada en 4 volumenes entre 1607 y 1624, éd. Vaganay (Genève : Slatkine Reprints, 1966), construye una sociedad hipotética al modo de otro tipo de novellas del género. Urfé utiliza como modelos las novelas pastorales como Il pastor fido de Guarini, Diana de Montemayor, Aminta de Tasso o Arcadia de Sannazaro y la Galatea de Cervantes. Véase: CLERC, Arto, «Engagements pastoraux et utopiques au XVII ${ }^{\mathrm{e}}$ siècle», Modern Language Notes Supplement, 2005, pp. 170-180. 
hacerse pastor y andarse por los bosques y prados cantando y tañendo, y, lo que sería peor, hacerse poeta, que, según dicen, es enfermedad incurable y pegadiza.

Pero ante la hipótesis del médico el padre contradice: «No quiero decir que no tengan una parte de culpa, pero es la mínima. Las óperas, señor Guillaut, le han reblandecido el cerebro. Ese canto, esos bailes, esas máquinas, esos dragones, esos héroes, esos dioses, esos demonios, la han descalabrado; su pobre cabeza no ha podido resistir tantas quimeras a la vez.» ${ }^{18} \mathrm{La}$ ópera es pues una variante de las novelas de caballerías llevada al extremo y Crisotine la tatarabuela de Madame Bovary.

Saint-Evremond no es el único que decide decantarse por la adaptación satírica y teatral de Don Quijote, lo original desde el punto de vista musicológico, consiste en la relación de contigüidad que establece el autor entre el género novelístico y la ópera a las que hace merecedoras de una crítica estética análoga. ${ }^{19}$

El momento de mayor intensidad crítica de esta reelaboración quijotesca no es la exposición de los efectos de tal psicopatología quimerófila, éstos tienen sobre todo la función de dar pie a situaciones cómicas en el desarrollo de la obra, sino el momento en que los allegados de Crisotine estudian el objeto desencadenante de la locura y discuten la forma de ponerle remedio. La criada Perrette y el médico deciden utilizar un método «literario», en el sentido estricto de la palabra. Perrette se hace con los «libros» de óperas de Crisotine y el médico comenta: «Como la locura de la señorita vuestra hija es muy parecida a la de Don Quijote, Perrette tiene razón al haber hecho con la ópera, lo que la buena sobrina y la criada hicieron con los libros de caballerías, y mientras esperamos a que la señorita se despierte, haremos el examen, siguiendo el ejemplo del cura y del maestro Nicolás.» ${ }^{20}$ Una comisión formada por el padre de la joven, Mr. Crisard y el médico, Mr. Guillaut, secundados por la madre y la criada, 〈representan〉 la escena del «escrutinio» tal y como aparece en el capítulo $6^{\circ}$ de la primera parte de Don Quijote ${ }^{21}$ La criada trae «los libros», la comisión los va inspeccionando y sometiendo a juicio uno por uno mientras enumera sus defectos, haciendo a la vez repaso de la historia más reciente de la ópera.

18. Les Opèras (véase nota 13), p. 59: «Mr. Crisard: Je ne voudrois pas dire qu'ils n'y eussent quelque part: mais c'est la moindre. Les Operas, Monsieur Guillaut, lui ont tourné la cervelle. Ce Chant, ces Dances, ces Machines, ces Dragons, ces Héros, ces Dieux, ces Démons, l'ont démontée; sa pauvre Tête n'a pû résister à tant de Chiméres à la fois»

19. Véase: PARADA, Arturo, Offene literarische Welten gegen geschlossene Denkmodelle und Sozialsysteme: Don Quijote und Anton Reiser, Frankfurt, Veurvert, 1997, pp. 92. Parada cita como obra más popular la sátira Hudibras de Samuel Butler, una sátira del puritanismo.

20. Les Opéras (véase nota 13), p. 61: «Mr. Guillaut: Comme la Folie de Mademoiselle vôtre Fille approche fort de celle de Don Quichotte, Perrette a eu raison de faire la même chose de Opera, que sirent la bonne Nièce, \& et la Servante, des Livres de Chevalerie; \& en attendant que Mademoiselle se réveille, nous en ferons l'exame, s'il vou plaît, à l'exemple du Curé, \& de Maitre Nicolas».

21. Ibidem, Acto $2^{\circ}$ escenas III y IV. 
Al llevar el paralelismo entre el tratamiento de la locura de Don Quijote y de Crisotine hasta este punto se ponen de manifiesto las limitaciones de la analogía entre los géneros, y con ello las diferencias pragmáticas y estéticas entre ellos. La escena del escrutinio en Don Quijote culmina en la imagen o al menos en la fantasía de una pira en que se consumen los libros. Para que la pira desarrolle el novelesco efecto disuasorio y purificador, al menos así lo imagino yo, ha de ser una pira grande, enorme y para ello son precisos entre otras cosas libros grandes. Los libros que trae Perrette no pasan de ser panfletillos en octava, puesto que transmiten únicamente el libretto de las óperas que han de ocupar el banquillo de los acusados. No se imprimieron partituras de ópera hasta bien entrado el siglo XIX, exceptuando, claro está, Orfeo de Claudio Monteverdi, que no sólo por esta razón es una obra excepcional. Permitiendo este «error» Saint-Evremond admite tácitamente que su crítica parte de un concepto de ópera en que ésta es considerada como idéntica a la novela: en este proceso de identificación la música es relegada a un plano que ni siquiera puede considerarse marginal, es más bien una suerte de inexistencia estética, y de este modo tanto la calidad estrictamente musical de la ópera como el conspícuo efecto sensible que la música ejerce carecen de importancia como elementos de juicio: lo nefasto de las óperas no es la presencia o ausencia de música sino el texto porque, al fin y al cabo, a un texto de calidad ¿para qué ponerle música?

Se escucha el canto con agrado, las palabras con disgusto. [...] no padeceremos eternamente ante el hecho de que el uso verdadero de la palabras sea anulado en el teatro. Nos dejaremos finalmente de tanta divinidad cantando y danzando, yo espero que les supliquemos respetuosamente se vayan a despachar sus asuntos en el cielo, y nos dejen a nosotros dedicarnos a los nuestros en la tierra. ${ }^{22}$

La crítica de Saint-Evremond es categórica: rechaza el género en su totalidad. Para él la ópera es en primer lugar un género teatral y el listón con el que debe medirse su calidad es el catálogo de criterios de los géneros tradicionales del teatro clásico: comedia y tragedia. La ópera está muy por debajo debido a la pobreza de su substancia literaria y a las limitaciones que la música impone a la comprensión de la poesía y a la expresión de sentimientos complejos o al menos diferenciados. La presencia estética y la lógica dramática del teatro lírico del siglo XVII difieren de las del teatro hablado: la sorpresa, el espectáculo como tal espectáculo, las máquinas, lo inexplicable, lo irreal y lo maravilloso sustituyen al modelo teatral clásico basado en la imitación de y la similitud con la naturaleza como medio de entretener, producir sentimientos

22. Ibidem, pp. 64s.: «Mr. Guillaut: On entendoit le Chant avec Agrément, les Paroles avec dégoût. [...] on ne souffrira pas éternellement, que le véritable usage de la Parole soit anánti sur le Théatre. Nous nous lasseron enfin, de tant de Difinités chantantes, \& dansantes: j'esere que nous le supplierons avec respect d'aller faire leur Mêtier dans le Cieux, \& de nous laisser faire le nôtre sur la Terre.» 
de identificación o de repulsa, compasión o ira, o burlarse de aquello que merece burla en las comedias, ofreciendo modelos de conducta moral al espectador que le ayuden a desenvolverse en su propia vida en el mejor de los casos o pongan en evidencia las excelencias de este u otro «príncipe» en la mayoría de ellos: delectare et prodesse. Al no poder cumplir las reglas de la dramática clásica tal y como dictan obras griegas y latinas, o los clásicos «modernos», la ópera merece desaparecer de los escenarios.

La ópera como vía muerta, como aberración en el desarrollo del teatro, he aquí el resumen de la opinión de Saint-Evremond. Observar la ópera desde un punto de vista teatral es, hasta cierto punto, legítimo dado que el género se nutre a partes iguales de elementos teatrales y musicales. Partiendo de su propia tradición cada uno de los espacios culturales receptores del género, combinó los elementos conocidos a fin de que el producto resultase plausible, comprensible y adecuado a la función social concreta que se le asignó en cada caso. De esta forma se fueron desarrollando modos muy diversos de exponer sobre el escenario historias contadas en y con música. Las preguntas que Saint-Evremond se abstiene incluso de plantear son, cual es la transformación esencial que la presencia de música impone a un texto escenificado y cómo es posible que tan «denostado» género como la ópera se convirtiese a pesar de ser objeto de tan rigurosos veredictos en el género musical más dinámico e importante del siglo XVIII y XIX. El ensalzamiento de la sinfonía como cima en el sistema de géneros musicales durante el romanticismo tuvo lugar a posteriori, para el compositor decimonónico la ópera siguió constituyendo el género musical por antonomasia, sólo un triunfo en la ópera cimentaba una carrera y valía más que cualquier colección de cuartetos de cuerda o cualquier revolución armónica o formal. Nadie echa de menos las inexistentes sinfonías de Richard Wagner, que Ludwig van Beethoven no contribuyese al género operísitico más que con un ejemplar problemático como «Fidelio», suele mencionarse como mínimo en una nota a pie de página y le convierten en un «especialista». ${ }^{23}$

Las opiniones de Saint-Evremond circularon en el mundo literario y musical alemán con cierto retraso. Pero su impacto en Alemania fue mucho más profundo y duradero que la influencia que ejercieran en vida del autor. La razón de esta tardanza no se debe sólo a que las obras no fueran publicadas hasta 1705, también es cierto que no existía la matrix científica, el clima intelectual adecuado para dar cabida al sentir y la línea argumental de Saint-Evremond y hacerlos fructificar hasta comienzos del siglo XVIII. Mientras el debate literario tiene en Inglaterra manifestaciones eruptivas ya a mediados del siglo XVII, en Alemania si bien se percibe y expresa ya en esta época la inquietud y la preocupación por ennoblecer la lengua vernácula o por suministrar un edificio de normas para la creación literaria, éstas se articulan en cír-

23. Véase en este contexto: DAHLHAus, Carl, Klassische und romantische Musikästhetik, Laaber, Laaber, 1988. 
culos intelectuales elitistas y tienen por consiguiente una repercusión social limitada. No será hasta las primeras décadas del siglo XVIII que la labor discreta de las sociedades de amigos de la lengua alemana, sociedades históricas, literarias, lingüísticas, todas ellas auspiciadas por ideales racionalistas e ilustrados, vaya adquiriendo rango académico y plasmándose por escrito en obras de cariz proto-enciclopédico. ${ }^{24}$ La canonización de la lengua alemana se cristaliza en las obras de uno de sus más influyentes representantes: Johann Christoph Gottsched, alumno de Gottfried Wilhelm Leibniz y Christian Wolf y seguidor del método sistemático de éste último, de su búsqueda de razones generales y últimas, de sistemas consistentes y cerrados, de la explicación única y generalizadora para los diversos fenómeno de la vida y del arte. ${ }^{25}$

El proyecto de Gottsched es tan ambicioso como poderosos son sus recursos para imponerlo, al menos en parte: nada menos que la canonización de la lengua alemana como lengua literaria y poética, la definición de reglas y leyes para la creación literaria, su ensalzamiento y la elevación del nivel intelectual de la sociedad en su totalidad. Los instrumentos para esta labor los encuentra en el racionalismo ilustrado cuyo fundamento legitimador es el estudio científico, la observación de la historia y la imposición de estrategias pedagógicas adecuadas para la educación de la juventud.

En su compendio Versuch einer Critischen Dichtkunst vor die Deutschen (Ensayo de una poética crítica para los alemanes) ${ }^{26}$, Gottsched resume las normas estéticas y suminstra baremos objetivos para definir la calidad del lenguaje: la base es histórica, el conocimiento de la literatura clásica y las normas dramáticas aristotélicas, la unidad de tiempo y lugar. La imitación de la naturaleza, la Nachahmungsästhetik, constituye la piedra angular de su edificio estético y poetológico. Siguiendo el método Wolfiano enumera e informa críticamente sobre todos los géneros literarios, muchos de ellos íntimamente ligados a la música como son las cantatas y las odas. La ópera, el tema con que cierra el libro, es la que, con diferencia, sale peor parada ejerciendo en su po-

24. Véase a propósito de la presencia de Don Quijote en este debate en Alemania PARADA (véase nota 16$)$, pp. $347 \mathrm{~s}$.

25. Las sociedades se orientan en el modelo de la Accademia della Crusca fundada en 1582 en Florencia. Las más importantes fueron: Fruchtbringende Gesellschaft (Weimar, 1617), Aufrichtige Tannengesellschaft (Estrasburgo, 1633), Musikalische Kürbishütte (Königsberg, 1636), Teutschgesinnte Genossenschaft (Hamburgo, 1643), Hirten- und Blumenorden an der Pegnitz. (Nürnberg, 1644), Elbschwanenorden (Hamburgo, 1656), Poetische Gesellschaft (Leipzig, 1677). Uno de los fines logrados por las sociedades fue la normalización de la ortografía alemana, Die deutsche Rechtschreibung (1645), y una genealogía de las lenguas alemanas, Der Teutschen Sprache Stammbaum und Fortwachs (1691). Se trata de sociedades igualitarias con ambición de servir sin ánimo de lucro. Véase con respecto al desarrollo de las sociedades lingüísticas en Hamburgo: RATHJE, Jürgen, «Zur hamburgischen Gelehrtenrepublik im Zeitalter Matthesons», New Mattheson Studies, ed. George J. Buelow y HansJoachim Marx, Cambridge, Cambridge University Press, 1983, pp. 101-122. Sobre la relación entre teoría estética y la filosofía de Christian Wolf: BIRKE, Joachim, Christian Wolfs Metaphysik und die zeitgenössische Literatur- und Musiktheorie: Gottsched, Scheibe, Mizler, Berlin, de Gruyter, 1966.

26. GoTTSCHED, Johann Christoph, Versuch einer Critischen Dichtkunst vor die Deutschen, Leipzig 1730, 1737, 1742, 1751, Schriften zur Literatur, ed. Horst Steinmetz, Stuttgart, Reclam, 1972. 
ética desde ese momento la función de cúmulo de vicios, de antítesis. ${ }^{27}$ Gottsched se sirve de los argumentos de Saint-Evremond al que cita como testigo de cargo: «Mi cuarto testigo sea Saint-Evremond. [...] porque ha escrito lo más fuerte que he encontrado contra las óperas.» ${ }^{28} \mathrm{En}$ el párrafo siguiente Gottsched cita la comedia Les Opéras, ofrece una sinopsis de la historia y una breve caracterización de la intención de la obra:

Pero [Saint-Evremond] no se da por satisfecho habiendo escrito una crítica sino que se toma incluso la molestia de escribir toda una comedia, a la que le pone el título les operas. Su intención consiste, como en el modelo de Cervantes con el Quijote, en poner en evidencia lo ridículo de las óperas [...] Estoy convencido de que hasta los más entusiastas amigos de la ópera no podrán contener la risa ante esta comedia. ${ }^{29}$

Gottsched se distancia de la crítica categórica de Saint-Evremond, alegando que más le habría valido al francés conceder, aunque sólo fuese por una cuestión de rigor científico, la diferencia entre óperas buenas y malas. En honor a la verdad, esta objeción deviene en retórica en boca de alguien como Gottsched, al que no le ha sido posible aislar un ejemplar vivo de <ópera buena〉. Las óperas buenas son pues una especie hipotética, inexistente o extinta.

Gottsched enriquece los argumentos de Saint-Evremond con observaciones específicas sobre la falta de adecuación de la lengua alemana, critica la manía de cantar en italiano o en una mezcla de varias lenguas y el hecho de que el texto finalmente no se entienda, independientemente de la lengua en que se cante debido a la profusión de trinos y gorgoritos. Los ejemplos con que ilustra la prosodia particularmente inadecuada de que hacen gala las óperas en Hamburgo le ponen la guinda a este decálogo de faltas, que hacen de la ópera lo más ridículo y prescindible que el arte humano haya creado jamás. El reproche más grave consiste en que sea la lógica músical la que en la ópera reina en el escenario, la razón es sustituida por una pseudo-razón que se articula cantando y no con argumentos racionales:

Queremos dedicarle unas palabras a los habitantes naturales de las óperas. No hablan más que cantando y caminan danzando, y en ocasiones hacen ambas cosas a un tiempo, cuando menos ganas tienen de hacerlo. Todos ellos obedecen al maestro musical del coro: un príncipe absoluto,

27. GotTsCheD, Johann Christoph, «Gedanken von Opern», en la edición de 1730, capítulo XII, pp. 710-736. Reproducido en: MizLER, Lorenz, Musikalische Bibliothek, 2, $3^{\text {a }}$ parte, 1742, pp. 1-49, relación completa del título en la nota 35.

28. Ibidem, pp. 24-25: «\$. 12. Mein viertes Zeugnis soll mir St. Evremond geben [...] Es ist werth, das ein ieder den ganzen Discurs lese, weil er das stärkste ist, was ich wieder die Opern gefunden habe.»

29. Ibidem, p. 25: «Er ist aber nicht zufreiden, daß er eine Critik darüber geschrieben hat; sondern hat sich gar die Mühe genommen, eine ganze Comödie zu machen, der er den Titel, les operas, gegeben. Seine Absicht darinn ist nach dem Muster des Cervantes in dem Quixote, das lächerliche der Opern empfindlich zu machen. [...] Ich bin versichert daß der gröste Opern-Freund sich bey einer solchen Comödien, des Lachens nicht enthalten können.» 
que, cuando mueve su cetro, consistente en un papel enrollado, elevándolo o haciéndolo descender, reina sobre los movimientos de un pueblo extrañísimo. Entre estas personas, la razón escasea. Porque tienen la cabeza llena de música, piensan un montón de canciones y hablan un montón de notas. Aun así han desarrollado un tan alto concepto de la razón que si fuese posible verter la razón en notas, podrían hablar racionalmente desde sus librettos. ${ }^{30}$

Primo la parola poi la musica, y esta máxima tiene para Gottsched como consecuencia que la dramaturgia operística haya de subeditarse por obligación a las normas poetológicas y dramáticas que rigen para el teatro en general, una ley que queda resumida en su célebre veredicto:

Si no queremos que las reglas de la poesía sean echadas todas ellas por al borda: Entonces me veo en la obligación de afirmar: La ópera es la creación más absurda que la razón humana ha inventado jamás. ${ }^{31}$

Gottsched no ahorra en referencias a la actualidad, con lo que nos devuelve al entorno geográfico y al escenario en el que comenzamos esta andadura:

Me congratulo de que la ópera en Alemania sufra paulatinamente una decaída. La ópera de Leipzig sucumbió hace muchos años y la ópera de Hamburgo está en las últimas. ${ }^{32}$

Duras palabras que suscitaron evidentemente las iras de todos los amantes del género e hicieron fluir ríos de tinta.

Escribimos el año 1730. Desde el comienzo de la ópera de Hamburgo hasta ahora la rudeza del tono ha permanecido constante pero los argumentos han sufrido una transformación significativa: la ópera ha dejado de ser un simple vehículo para convertirse en objeto al que se le dedica un crítica específica, que paradójicamente le concede a la ópera un derecho de ciudadanía en el canon de los géneros artísticos: sólo lo que se toma en serio merece esfuerzo crítico. Una segunda diferencia entre la primera y la segunda ofensiva contra la ópera comienza a hacerse patente a principios del siglo XVIII. El pastor

30. Ibidem, p. 30: «Wir wollen noch ein Wort von den natürlichen Einwohnern der Opern sagen. Sie reden nicht anders als singend, sie gehen tanzend, und thun offt beydes, wenn sie die wenigste Lust dazu haben. Sie gehorchen alle dem Meister des musikalischen Chors: einem sehr unumschränkten Prinzen, der, wenn er seinen Zepter, der aus einer Rolle Papier bestehet, hebt oder seinken läßt, alle Bewegungen dieses wunderlichen Volkes regieren. Die Vernunfft ist unter diesen Leuten rar. Weil sie den Kopf ganz voller Music haben; so denken sie lauter Lieder, und sprechen lauter Töne. Dem ohngeachtet haben sie die Vernunft so hoch getrieben, daß, wenn die Vernunft in Noten könnte gebracht werden; sie aus Opernbüchern vernünftig würden reden können.»

31. Ibidem, p. 10: «Wenn nicht die Regeln der ganzen Poesie übern Hauffen fallen sollen: So muß ich sagen: Die Opera sey das ungereimteste Werk, so menschlicher Verstand iemals erfunden hat»

32. Ibidem, p. 34: «Ich erfreue mich aber, wenn das Operwesen in Deutschland mehr und mehr in Abnahm geräth. Das Leipziger Operntheater ist seit vielen Jahren eingegangen, und das hamburgische liegt in den letzten Zügen.» 
Reiser era un clérigo, Saint-Evremond y Gottsched son estudiosos de la literatura. Mientras el empresario de la ópera de Hamburgo tiene que recurrir a ayuda externa para salvar su espectáculo, a partir de 1710 son los propios músicos los que desenvainan sus espadas para salvar el honor de la ópera. Vemos surgir la primera generación de músicos letrados que consideran la música un arte más emparentado con la literatura y el discurso histórico y estético que con las matemáticas, con las que desde el establecimiento del canon de artes liberales como estructura del saber había tenido que cohabitar en el cuarteto de las artes quadriviales, si no es que se la trató más como oficio artesanal que como actividad artística. Esta generación de músicos adopta sus medios de articulación y de divulgación de sus nuevos «primos-hermanos», los críticos literarios. Siguiendo el ejemplo de las sociedades históricas y literarias y el ejemplo de Gottsched se fomenta el intercambio y la correspondencia, y se publican a partir de 1720 gran cantidad de compendios y tratados dedicados en primer término a elevar la música, y a conquistar un espacio propio dentro del canon de la erudición ilustrada.

En 1713 Johann Mattheson hace una primera referencia crítica a Saint-Evremond y a Les Opéras. No hace falta profundizar en la obra en cuestión para percibir el cambio de espíritu y el nuevo estatus que Johann Mattheson reivindica para sí mismo y sus correligionarios, basta con observar el título de su tratado:

La nueva orquesta o la instrucción universal y minuciosa para que el hombre galante pueda adquirir un concepto completo de la diginidad y majestad de la sublime música, pueda formar en ella el gusto / entender los términos técnicos y razonar ingeniosamente sobre esta noble ciencia. ${ }^{33}$

Mattheson no se deja amedrentar por la superioridad tradicional de los hommes de lettres con respecto a un simple musicien. Al argumento de SaintEvremond: «No le quiere entrar en la cabeza por ejemplo [...] que alguien golpée y apuñale a alguien siguiendo el compás» Mattheson responde con gran aplomo: «se podría decir de la poesía lo mismo que en este contexto se critica en la música [...] a nadie se le ocurriría tampoco apuñalar en la realidad a alguien en verso.» ${ }^{34}$

Pero habrá que esperar a 1730, a la publicación del Versuch über die Critische Dichtkunst para que el conflicto madure y desarrolle todos sus elementos. Un estímulo decisivo supuso la actividad divulgadora y organizadora de

33. MAtTHESOn, Johann, Das Neu-Eröffnete Orchestre, oder Universelle und gründliche Anleitung Wie ein Galant Homme einen vollkommenen Begriff von der Hoheit und Würde der edlen Music erlangen, seinen Gout darnach formiere / die Terminos technicos verstehen und geschicklich von dieser vortrefflichen Wissenschaft raisonnieren möge, Hamburgo 1713, edición facsimilar, Laaber, Laaber, 2004.

34. Ibidem, pp. 164s.: «Da mochte es ihnen unter anderen nicht in den Kopf, daß zum Exemple [...] einer den anderen nach dem Tact erschlüge und ersteche. [...] Allein, hierauf dienet (1.) dass man solcher Gestalt eben das von der Poësie sagen könnte, was man in hoc passu an der Music tadeln will; daß nemlich [... niemand] den andern re verâ reimweise erstechen [würde].» 
Lorenz Mizler, tanto como difusor de textos con la publicación periódica $\mathrm{Mu}$ sikalische Bibliothek (Biblioteca musical) (1736-1754) como en su función de fundador y precursor de la Sozietät der Musicalischen Wissenschaften (Sociedad de ciencias musicales) fundada en 1738, una asociación cuyos fines y medios reproducen las fórmulas acuñadas por las sociedades literarias e históricas. ${ }^{35}$ La comunidad de acólitos dirige sus ojos igualmente hacia modelos creados por la crítica literaria cuando define la forma que deben tener sus textos, reproduciendo los tipos y género de textos, el tono de la discusión y la agenda de prioridades. Scheibe alude con su Critischer Musikus al título de Gottsched, Versuch über die Critische Dichtkunst, y no es casualidad ni que Mizler denomine su publicación «Bibliothek» en lugar de recurrir a un sustantivo especificamente musical, ni que dedique este órgano primordialmente a discutir libros y no obras musicales: los músicos pretenden hablar a la altura de los literatos y para ello no sólo copian sus estructuras sino también su discurso, sus argumentos y sus temas. La crítica literaria a su vez ha forjado sus instrumentos de divulgación y los géneros para alcanzar al público observando sobre todo el caso inglés y la tradición de semanarios morales. Los primeros pasos de la crítica literaria consisten en traducir revistas periódicas como The Tatler o The Spectator o en realizar versiones germánicas como Der Patriot de Barthold Hinrich Brockes, o Die vernünftigen Tadlerinnen (las críticas juiciosas) o Der Biedermann, ambas editadas por Johann Christoph Gottsched, que van preparando el terreno y al público para publicaciones de mayor envergadura. ${ }^{36}$

La Musikalische Bibliothek sirve de multiplicador y de filtro para canalizar la discusión y para introducir textos literarios e históricos en el discurso musical. En la tercera entrega Mizler publica un texto programático de Johann Mattheson: Schrifft von der musikalischen Gelehrtsamkeit (Escrito sobre la erudición musical), una carta abierta escrita en 1732 a Johann Christoph Krüsike, en la que Mattheson reivindica la inclusión de la música en el canon de las ciencias y la rehabilitación de la música alemana con respecto a la música de otras naciones. ${ }^{37}$

Mizler reproduce uno tras otro en su Biblioteca los capítulos de la poética de Gottsched relevantes para la música: en 1738 los ensayos sobre las odas y las cantatas, en 1742 aparece el capítulo dedicado a las óperas: Herrn Professor Gottscheds Gedanken von Opern (Las ideas del Professor Gottsched sobre las óperas). ${ }^{38} \mathrm{El}$ adjetivo <imparcial〉 que reza en el título de la publicación de Mizler

35. MizLER, Lorenz, Musikalische Bibliothek. [2 ${ }^{\circ}$ y $3^{\text {er }}$ Volumen, Neu Eröffnete Musikalische Bibliothek] Oder gründliche Nachricht nebst unparteheyischem Urtheil von alten und neuen musikalischen Schriften und Büchern, 4 vols., Leipzig, 1, [1736-1738] 1739; 2, [1740-1743] 1743; 3, [1746-1752] 1752; 4, 1754, edición facimilar, Hilversum, Knuf, 1966.

36. GotTsched, Johann Christoph, Die vernünftigen Tadlerinnen, 2 vols., Halle y Leipzig, 1725-1727; Der Biedermann, Leipzig, 1728-1729.

37. Mattheson, Johann, «Schrifft von der musikalischen Gelehrsamkeit», Musikalische Bibliothek, ed. Lorenz Mizler, vol. 1, 3a parte, 1736, pp. 6-16 (véase nota 35).

38. GotTsChed, Johann Christoph, «Herrn Professor Gottscheds Gedanken von Opern», Musikalische Bibliothek, ed. Lorenz Mizler, 2. vol. 3a parte pp. 1-49 (véase nota 35). Los capítulos sobre las odas y las cantatas aparecen en el primer volumen en las partes 5 a y 6 a respectivamente. 
es, como se verá, más un elemento propagandístico que una declaración de principios inflexibles. Tras haber minado el campo con las pullas de Gottsched tan sólo hace falta esperar a que caigan las réplicas cual fruta madura. ${ }^{39}$

La influencia de Gottsched en el mundo académico, literario y artístico, poderosísima en las primeras décadas del siglo, había mermado considerablemente desde mediados de los años 30 debido a críticas desde dos bandos: los teólogos que le consideran demasiado racionalista y librepensador y los partidarios de una nueva poética liberada de las normas aristotélicas y de la dependencia a la estética de la imitación. Gottsched empero no ceja en su empeño de erigirse en árbitro y legislador en el escenario alemán, sin olvidar nunca su aversión contra las óperas. Viendo lo difícil que resultaba triunfar en campo ajeno, vuelve al ataque pero esta vez en su propio territorio. En el segundo volumen de su colección de textos dramáticos ejemplares, Die deutsche Schaubühne nach den Regeln der alten Griechen und Römer eingerichtet (El escenario alemán dispuesto según las reglas de los antiguos griegos y romanos) publica en 1742 una traducción al alemán de la comedia Les Opéras de Charles de Saint-Evremond tras haberle practicado las transformaciones pertinentes: traslación de lugar - de Lille a Lübeck, una ciudad de provincias cerca de Hamburgo - y de tiempo: de los años 70 del siglo XVII y los años 40 del siglo XVIII. ${ }^{40}$ Ya que no puede vencer a sus adversarios a base de argumentos, al menos intentará hacerles reír, y esto nunca sin segunda intención, quién sabe, a lo mejor se mueren de risa.

Nuestra mademoiselle Quijote se ha convertido en Fräulein Lottchen y en lugar de frecuentar la ópera de París es asidua a la ópera de Hamburgo. Si bien sigue cantando arias y recitativos de Cadmus et Hermione, vertidos al alemán, por supuesto, su biblioteca está repleta de los libretos de las óperas de Hamburgo y son estos libretos los que el padre y esta vez de nuevo el estamento

39. Las réplicas directas publicadas en LORENZ MizLer, Musikalische Bibliothek están firmadas por Hudemann, Ludewig Friederich, «Gedanken von den Vorzügen der Opern vor Tragedien und Comedien», Musikalische Bibliothek, ed. Lorenz Mizler, 2o vol. 3a parte, 1743, pp. 120-151 (Reflexiones sobre las ventajas de la ópera comparada con las tragedias y comedias) y por UFFENBACH, Friedrich von, «Von der Würde derer Singegedichte oder Vertheidigung der Opern», Musikalische Bibliothek, ed. Lorenz Mizler, 3er vol. 3a parte, 1752, pp. 377-408 (A próposito de la nobleza de los poemas cantados y apología de las óperas). Véase a este respecto: LÜTTEKEN, Laurenz, «Poesie als Klang: Johann Friedrich von Uffenbachs Gottsched-Replik und Telemanns Opernschaffen», Telemann in Frankfurt. Bericht über das Symposium. Frankfurt am Main, 26.-27. April 1996, ed. Peter Cahn, Mainz et al., Schott, 2000, pp. 248-259.

40. Saint-Evremond, Charles de, «Die Opern, Ein Lustspiel von fünf Aufzügen», traducido por Johann Christoph Gottsched y una amiga anónima, Die Deutsche Schaubühne, vol. 2, Leipzig 1742, pp. 77-162.

Véase en este contexto: SEIDEL, Wilhelm, «Saint-Evremond und der Streit um die Oper in Deutschland», Aufklärungen. Studien zur deutsch-französischen Musikgeschichte im 18. Jahrhundert - Einflüsse und Wirkungen, vol. 2, ed. Wolfgang Birtel y Christoph-Hellmut Mahling, Heidelberg, Winter, 1986, pp. 46-54. WolfF, Hellmuth Christian, «Die Komödie Les Opera (1677) des SaintEvremond und ihre deutsche Fassung von Gottsched (1741)», Festschrift Heinz Becker zum 60. Geburtstag am 26. Juni 1982, ed. Jürgen Schläder y Reinhold Quandt. Laaber, Laaber, 1982, pp. 26-37. 
eclesiástico personificado en un pastor protestantes someten a escrutinio. Gottsched, llevado por su prurito de científico riguroso, se ha informado a conciencia sobre el objeto que le ocupa, en la misma publicación en que aparece su traducción de Les Opéras, publica un registro de las óperas representadas en Hamburgo desde la fundación de la Oper am Gänsemarkt en 1678 hasta 1719.41

Faltan obviamente las óperas posteriores, entre ellas dos de las adaptaciones de Don Quijote de más éxito: la ópera de Bartolomeo Conti y la adaptación de Georg Philipp Telemann, lo que, por otra parte, las salva de la quema. Los capítulos dedicados al escrutinio son los que sufren mayores transformaciones en la versión alemana y es significativo que Gottsched mencione los nombres de los autores literarios, olvidando en cambio los nombres de los compositores. Aunque cantar sea el síntoma más aparente de la enfermedad de Lottchen, es sólo un síntoma y no la enfermedad. Lo realmente grave es la infiltración con textos inadecuados, algo imperdonable en la educación de una señorita. Gottsched sabe exactamente lo que una señorita debe y no debe leer. Y no duda en publicar su bibliografía oficial para señoritas en la Moralische Wochenschrift, el semanario moral Der Biedermann bajo el pseudónimo de Ernst Wahrlieb Biedermann, en la séptima entrega, fechada el 16 de junio de 1727. En 1725, en el semanario moral Die vernünftigen Tadlerinnen aún encontramos entre un sinfín de libros franceses Don Quijote en la lista de lecturas recomendadas para las damas. En 1727 ha cambiado de opinión restringiendo el espectro de temas radicalmente: El tratado del Padre Dupuis para la instrucción de señoritas, en francés para que de paso aprendan la lengua, obras edificantes escritas por mujeres y obras escritas ex profeso para mujeres en francés y en alemán. Por último obras divulgativas para aumentar sus conocimientos sobre el saber universal, die Weltweißheit, escritas en verso para que sean más amenas y más fácil su estudio, se le suman crónicas, descripción de viajes, textos espirituales. Brillan por su ausencia tanto las obras de los clásicos, la filosofía, la teología y cualquier tipo de prosa ficcional: pastorales, sátiras, novelas. ${ }^{42}$ La única música que conoce una señorita bien educada es la música religiosa y la música interpretada en su propia casa, la Hausmusik. Evidentemente no son sólo las mujeres las que, según Gottsched, precisan de correctivo pedagógico, pero la 〈jovencita〉 representa en la cadena del racionalismo el eslabón más débil y más susceptible a dejarse llevar por ideas nebulosas y estéticas sensualistas y mientras en la educación de los jóvenes la disciplina física y el contacto con la naturaleza regulan los apetitos fisiológicos de forma natural, en el caso de las mujeres no hay un contrapeso corporal con el que compensar los instintos sensuales, que por ello, sólo son controlables a base de censurar la lectura y el ejercicio musical.

41. GotTSCHED, Johann Christoph, «Register aller Opern, welche in Hamburg aufgeführet worden», Die Deutsche Schaubühne, vol. 2º, Leipzig 1742, pp. 73*-77*.

42. GotTsCheD, Johann Christoph, Der Biedermann, 7a entrega 16 de junio 1727. 
El valor paradigmático de Les Opéras reside para Gottsched en primer término en que demuestra la pésima influencia que textos inadecuados pueden tener en el espíritu. Vestirlos con ropaje operístico sólo hace de algo malo algo peor. Ecuchemos de nuevo a Johann Adolph Scheibe en el Critischer Musikus, quien hace de portavoz de las posiciones gottschedianas en el ámbito musical:

De este modo el público acabo confundido, y el mal gusto empezó a dominar, uno que no consideraba bueno, lo que no estuviese repleto de maravillas manidas. De este modo las maravillas naturales fueron exiladas y se eligieron en cambio miles de cosas imposibles, que contradicen obviamente a la naturaleza y la razón, y que ni siquiera corresponden a la imaginación fantástica. ${ }^{43}$

Estas palabras que Scheibe escribe pensando en las óperas se ajustan perfectamente a la crítica racionalista ilustrada contra las novelas. La lucha entre la estética de la imitación a la naturaleza y la razón como paradigmas narrativos y lo maravilloso, das Wunderbare, le merveilleux, como producto privilegiado de la imaginación no es otra que el conflicto que se dirime en la Querelle des Ancienne et de Modernes. La reinterpretación que los críticos Johann Jakob Bodmer y Johann Jakob Breitinger hacen de Don Quijote, su reivindicación de lo maravilloso, y del poder de la imaginación, prefigura de algún modo el desarrollo que tendrá la discusión sobre la ópera en Alemania. Mientras Don Quijote sirve de argumento en contra de la estética de lo maravilloso y de la ópera en la primera mitad del siglo XVIII, su función sufrirá una transformación radical en la segunda. El arma se convierte en aliado.

En la cita con que comienza esta texto Johann Mattheson le reserva a Don Quijote un lugar específico, excepcional en el firmamento estético de la época - «su propia libertad aventurera» - al márgen de las discusiones sobre la mímesis y no duda en generalizar esa liberación desdiciéndose de las limitaciones que la estética de la verosimilitud le impone a la creación musical. Concediéndole la palabra a un corresponsal anónimo para que manifieste abiertamente su apoyo incondicional a la ópera, Mattheson da el primer paso hacia una estética musical autónoma:

Cierto es que ha alegrado mi corazón en particular lo que leí sobre todo a partir de la página 19 hasta el final en dónde se trata el párrafo en contra de la inverosimilitud con tan despierta concisión que no veo qué razones cabales en contra podrían aducir los defensores de las sentencias que S. Maj.

43. SCHEIBE, Johann Adolph, Critischer Musicus, (véase nota 2), p. 224: «Hierdurch ward der Zuschauer verwirrt gemacht, und es bekam zuletzt ein übeler Geschmack die Oberhand, der nichts für gut hielt, was nicht mit diesem abgeschmackten Wunderbaren angefüllet war. So verbannt man also das natürliche Wunderbare und erwählt statt dessen tausend Unmöglichkeiten, die mit der Natur und Vernunft augenscheinlich stritten, und die auch nicht einmal mit einer fantastisch Einbildung übereinstimmten.» 
el Naturalismo pedantico ha pronunciado en contra de las óperas y la de dientes que se romperán los Señores Muratorizantes con estas nueces. Vivat vindex $\mathrm{M}-\mathrm{s}$ ! ${ }^{4}$

Lodovico Antonio Muratori observa desde la periferia el desarrollo de la ópera en Italia y Viena por su amistad con el libretista y poeta de la corte imperial vienesa Apostolo Zeno, quien contribuyó a la definición poetológica de la opera seria italiana y a su difusión en centroeuropa. La opera seria adquiere su forma canónica en las obras de Pietro Metastasio, sucesor de Zeno en Viena. El modelo consiste en la narración de un hecho histórico o mitológico de carácter heroico en que el buen tirano resuelve un conflicto entre deber político y sentimiento aparentemente insoluble y logra por medio de una decisión clemente que el conflicto desemboque en un convencional lieto fine. Los dioses y las máquinas han sido relegados felizmente a un mero papel ornamental, aunque esto no signifique que las decisiones de los «humanos» no puedan ser tan sorprendentes y faltas de motivación psicológica como lo fueran las acciones de dioses encaramdos a máquinas voladoras que aparecen en el escenario repartiendo a diestro y siniestro rayos y centellas. Aun así la reducción de los elementos numinosos, tan dominantes en la diégesis de la Tragedie Lyrique, constituye un acercamiento a los dictados de la verosimilitud, un compromiso con la crítica literaria que Mattheson rechaza por innecesarios: la coherencia de la ópera está implícita en la lógica musical.

Lejos ya el tiempo en que los músicos se humillan servilmente ante las «cien veces recalentadas críticas evremónticas» o los «denuestos zwinglianos» de los pietistas hamburgueses, Mattheson reivindica para las óperas la misma libertad aventurera que le concede a Don Quijote y no duda en contraponer a las críticas de Gottsched «las leyes verdaderas del arte musical». ${ }^{45}$ Para enfrentarse al desprecio que el mundo literario manifestaba ya sea por desconocimiento o por ignorancia activa por el arte musical compila ya en 1740 el primer panteón de músicos famosos de su tiempo la Grundlage einer Ehrenpforte (Pedestal para un arco triunfal), obra en la que encontramos entre las biografías de otros 148 músicos la primera nota biográ-

44. Mattheson, Johann, Die neueste Untersuchung der Singspiele, Hamburgo 1744, edición facsimilar, Kassel, Bärenreiter, 1975,.p. 2s. «Wahr ists, daß ich mich von Herzen gefreuet über alles, was insodernheit von der 19 Seite, wo der §. wieder die Unwahrscheinlichkeit anhebet, bis zu Ende, mit solcher aufgeweckten Bündigkeit, abgehandelt worden, daß ich nicht sehe, was die Verfechter der von Sr. Maj. dem Naturalismo pedantico, wider die Singspiele gesprochenen Sentenz weiter mit raison beginnen wollen, und was die Herren Muratorizantes an diese Nüsse für Zähne wagen werden. Vivat vindex $\mathrm{M}-\mathrm{-s}$ !»

45. Mattheson, Johann, Die neueste Untersuchung der Singspiele, Hamburgo, 1744, p. 37 : «Allein, daß daran die wahren Lehrsätze heutiger Tonkunst und die Ungeschicklichkeit derer die sie recht inne haben, Schuld seyn sollten, das ist eine Beleydigung, ohne allen Unterscheid; ein großer Irrthum; sowohl, als die hundertmal aufgewärmeter evremontische und zwinglianische Grillen, von der unnatürlich angegebenen und unwahrscheinlich vermeynten Art des Singens auf dem Schauplatz und Kirchenchor.» 
fica y el más prematuro juicio histórico sobre Johann Sebastian Bach en vida del compositor. ${ }^{46}$

Mientras Pietro Metastasio ha sido erigido en modelo para la opera seria los intentos de reforma desde el norte intentan adaptar las formas musico-dramáticas Metastasianas a la música vocal alemana y a sus tradiciones desde diferentes puntos de partida. Y antes incluso de que Daniel Schiebeler y Johann Adam Hiller saquen a la luz su primera «romantisch-comische Oper» en lengua alemana, Lisuart und Dariolette ${ }^{47}$, el octogenario Georg Philipp Telemann compone una pequeña obra de arte, una ópera «romántica» en miniatura, en la que ya se observan primeros atisbos de la independización del ideal de la opera seria: el 5 de noviembre de 1761 se estrena en Hamburgo en el «Musik Saale auf der Dreyerbahn» la serenata Quichotte auf der Hochzeit des Comacho (Don Quijote en las bodas de Camacho), una ópera «romántica» alemana avant la lettre. ${ }^{48}$

No sin desviarse a derechas e izquierdas el ascenso de una estética de la autonomía musical culminará en la glorificación de la música como medio para la expresión humana, o incluso como objetivación de la voluntad en sí misma, del «Wille an sich» en la filosofía de Arthur Schopenhauer o como lenguaje privilegiado que transpasando los límites de lo conceptualizable se adentra en el lenguaje inefable del espíritu, «die geheimnisvolle Sprache eines fernen Geisterreiches», el enigmático lenguaje de un lejano reino fantasmal, que E.T.A. Hofmann conjura en boca de un ficticio Ludwig van Beethoven en sus divagaciones estético-musicales. ${ }^{49}$

La crítica musical alemana, liderada por autores elocuentes y de juicio preciso como Mattheson, tuvo una influencia extraordinaria en el ambiente intelectual germánico instalando el ideal musical como elemento constituyente necesario en la reflexión filosófica, literaria y estética. En el pensamiento de la ilustración germánica de finales del siglo XVIII, en un

46. Johann, Mattheson, Grundlage einer Ehrenpforte, Hamburgo 1740, edición facismilar, ed. Max Schneider, Kassel et al., Bärenreiter, 1969.

47. El estreno tuvo lugar el 25 de noviembre de 1766 en Hamburgo.

48. LÜTTEKEN, Laurenz, «Metastasio im Spannungsfeld der deutschsprachigen Opernkritik des 18. Jahrhunderts», Metastasio im Deutschland der Aufklärung. Bericht über das Symposium Potsdam 1999, Eds. Laurenz Lütteken y Gerhard Splitt, Tübingen, Niemeyer, 2002, pp. 141-155. (Wolfenbütteler Studien zur Aufklärung, 28), pp. 153s.

49. Véase Schopenhauer, Arthur, Die Welt als Wille und Vorstellung $(1819,1844)$, el mundo como voluntad y representación; Hofmann, E.T.A., «Der Dichter und der Komponist», (1813), E.T.A. Hofmanns musikalische Schriften, ed. E. Istel, s. 1. s. d., pp. 40s.: «Ludwig. Ist nicht die Musik die geheimnisvolle Sprache eines fernen Geisterreichs, deren wunderbare Akzente in unserm Innern wiederklingen und ein höheres, intensives Leben erwecken? Alle Leidenschaften kämpfen schimmernd und glanzvoll gerüstet miteinander und gehen unter in einer unaussprechlichen Sehnsucht, die unsere Brust erfüllt.» «Ludwig: ¿No es acaso la música el enigmático lenguaje de un lejano reino fantasmal cuyos maravillosos acentos reverberan en nuestro interior despertando una más elevada, más intensa vida? Todas las pasiones luchan en titileante y resplandeciente armadura y sucumben al anhelo innombrable que llena nuestro pecho.» Véase a este respecto: NiEdermüller, Peter, Die Oper im Lichte von Schopenhauers Musikästhetik, Tesina, Würzburg, 1994, p. 18. 
ambiente intelectual en que la reflexión estética e incipientes inquietudes nacionalistas se refuerzan mutuamente, la creación de una ópera alemana se convierte en un desideratum. No son pocos los que se aplican personalmente en buscar soluciones concretas a este «problema». Es no obstante revelador que la avanzadilla de este movimiento esté ocupada por los príncipes de las letras secundados a gran distancia por compositores hoy totalmente olvidados: Christoph Martin Wieland y Johann Wolfgang von Goethe toman la iniciativa y escriben incansablemente libretos que sin excepción quedaron encerrados en un extraño limbo historiográfico, como santos inocentes incapaces de sobrevivir si se les corta el cordón umbilical. Es una ironía de la historia musical germánica que las inquietudes operísticas del alto clasicismo alemán no fraguasen debido precisamente a que su texto y los autores literarios tenían un peso específico muy superior a la música y los compositores: Philipp Christoph Kayser, Ernst Wilhelm Wolf, Johann Adam Hiller, Anton Schweitzer son tan desconocidos como las óperas Alceste, Pandora, Rosamunde, Die Wahl des Herakles de Christoph Martin Wieland o Scherz, List und Rache, Jery und Bätely, Die Fischerin de Goethe. ${ }^{50}$ Hay que tener presente este ambiente de efervescencia, esta preocupación constante, esta actividad casi obsesiva alrededor de la ópera alemana para comprender el impacto infinito que tuvo, tras un primer conato subversivo con la «Reformoper» de Christoph Willibald Gluck, en la generación de Goethe la aparición de las primeras ópera alemanas suficientemente vitales para respirar por si mismas: Wolfgang Amadeus Mozart logra con El rapto del serrallo, 1785 y La flauta mágica, 1791 cortar el nudo gordiano con una superioridad inusitada demostrando de un plumazo que la ópera alemana era posible, al tiempo que da fe de un riqueza de registros dramáticos intrínsecamente musicales y una intuición infalible para la escena sin precedentes.

Quien observe el valor paradigmático que adquiere la música en el pensamiento del romanticismo alemán, en autores como Johann Wolfgang Goethe, Johann Gottfried Herder, Arthur Schopenhauer o Friedrich Nietzsche no tardará en reconocer que fue en el siglo XVIII cuando se allanó el camino para que la música se convirtiese para el discurso filosófico en el paradigma de la expresión auténtica de sentimientos humanos inefables y sublimes y en la más pristina superficie de identificación nacional en un país que carecía de modelos históricos o políticos sobre los que proyectar sus anhelos unificadores como era Alemania en proceso de consolidación política.

Mas el proceso de reubicación del paradigma quijotesco en la estética operística no se desarrolla de modo tan lineal como a la historiografía musical le

50. Véase en este contexto: Bauman, Thomas, North German Opera in the Age of Goethe, Cambridge, Cambridge University Press, 1985; Hartmann, Tina, Goethes Musiktheater. Singspiele, Opern, Festspiele, «Faust», Tübingen, Niemeyer, 2004, (Hermaea. Neue Folge, Bd. 105); KRÄMER, Jörg, Deutschsprachiges Musiktheater im späten 18. Jahrhundert. Typologie, Dramaturgie und Anthropologie einer populären Gattung, Tübingen, Niemeyer, 1998, (Studien zur deutschen Literatur 149/150) 
gustaría. En una crítica de la ópera Xindo riconosciuto publicada en 1766 leemos:

Pero tras haber leído el argumento se me ocurre, y me resulta incluso muy posible que el autor conocía bien algunas novelas estrafalarias en las que se habla de caballeros andantes. ${ }^{51}$

Afirmación que un crítico del crítico se atreve a modificar significativamente:

El señor crítico intenta ridiculizar al poeta acusándole de haber leído muchas novelas estrafalarias sobre caballeros andantes que le proporcionaron el material para escribir su texto. Yo me atrevo en cierto modo a darle la vuelta a esta frase: quien escribe una novela inverosímil, en suma; mala, debe haber leído sin lugar a dudas muchas óperas. ${ }^{52}$

No sólo la opinión de Gottsched sobre las óperas, también el medio de la lectura como forma de recepción de la ópera mantienen su vigencia en la discusión. El hecho de que sea la lectura, que el melólogo, musicólogo y purista considera una forma de recepción secundaria, inadecuada al objeto estético la que se utilice aquí como tertium comparationis entre la literatura y la música constituye uno de los puntos neurálgicos de la disputa y a la vez uno de sus puntos débiles. Obviar este detalle convierte un malentendido fructífero en una callejón sin salida.

Nada es tan fácil como parece y la persistencia de esta discusión da fe de que por mucho que la narración historiográfica haya soslayado con su perspectiva unívocamente teleológica la simultaneidad de paradigmas, la dicotomía entre la verosimilitud y la fantasía, entre la naturaleza y la ficción es una constante en la discusión estética y Don Quijote como figura de pensamiento firmemente arraigada en el imaginario seguirá cabalgando por las páginas de los críticos operísticos por mucho tiempo, aunque su montura cambie con las modas.

\section{BIBLIOGRAFÍA CITADA}

Bauman, Thomas, North German Opera in the Age of Goethe, Cambridge, Cambridge University Press, 1985.

51. R.S., en HiLleR, Johann Adam, Wöchentliche Nachrichten und Anmerkungen die Musik betreffend, $6^{\mathrm{a}}$ parte, Leipzig, 5.8.1766, p. 43: «Doch bey Durchlesung des Arguments fällt mir ein, und kommt mir fast glaublich vor, daß der Herr Autor mit einigen trolligten Romanen, worinn von irrenden Rittern gehandelt wird, müsse bekannt gewesen seyn.»

52. N.N., en, ibidem, $16^{\mathrm{a}}$ parte, Leipzig, 14.10.1766, pp. 123s.: «Der Herr Recensent sucht den Dichter lächerlich zu machen, indem er ihm Schuld giebt, er müsse sehr viel drollige Romanen von irrenden Rittern gelesen haben, die ihm den Stoff zu diesem Gedicht an die Hand gegeben hätten. Ich möchte diesen Satz beynahe umkehren und sagen, wer einen unwahrscheinlichen oder kürzer, einen schlechten Roman schreibt, der muß gewiß viel Opern gelesen haben.» 
BIRKe, JoAchim, Christian Wolffs Metaphysik und die zeitgenössische Literatur- und Musiktheorie: Gottsched, Scheibe, Mizler, Berlin, de Gruyter, 1966.

ClERC, ARTO, «Engagements pastoraux et utopiques au XVII ${ }^{\mathrm{e}}$ siècle», Modern Language Notes Supplement, 2005, pp. 170-180.

DAHLHaus, CARL, Klassische und romantische Musikästhetik, Laaber, Laaber, 1988.

DöHRING, SiEgHART, «Theologische Kontroversen um die Hamburger Oper», Festschrift Klaus Hortschansky zum 60. Geburtstag, ed. Axel Beer y Laurenz Lütteken, Tutzing, Hans Schneider, 1995, pp. 111-123.

GotTsCHED, JohANn CHRISTOPH, Der Biedermann, semanario moral, Leipzig, 1728-1729.

GotTsched, Johann Christoph, Die vernünftigen Tadlerinnen, 2 vols, Halle/Leipzig, $1725-1727$.

GOTTSCHED, JOHANN CHRISTOPH, «Register aller Opern, welche in Hamburg aufgeführet worden», Die Deutsche Schaubühne, vol. 2, Leipzig, 1742, pp. 73*-77*.

GOTTSCHED, JoHANN CHRISTOPH, Versuch einer Critischen Dichtkunst vor die Deutschen, Leipzig, 1730, 1737, 1742, 1751, Schriften zur Literatur, ed. Horst Steinmetz, Stuttgart, Reclam, 1972.

Hartmann, Tina, Goethes Musiktheater. Singspiele, Opern, Festspiele, «Faust», Tübingen, Niemeyer, 2004, (Hermaea. Neue Folge, Bd. 105).

HiLler, JoHANN ADAM, Wöchentliche Nachrichten und Anmerkungen die Musik betreffend, Leipzig, 1766-1768.

Hofmann, ERnst Theodor Amadeus, «Der Dichter und der Komponist», E. T. A. Hofmanns musikalische Schriften, ed. Edgar Istel, s. 1. s. d., pp. 32-45.

Hudemann, Ludewig Friederich, «Gedanken von den Vorzügen der Opern vor Tragedien und Comedien», Musikalische Bibliothek, ed. Lorenz Mizler, 2o vol. 3aㅡ parte, 1743, pp. $120-151$.

KRÄMER, JÖRG, Deutschsprachiges Musiktheater im späten 18. Jahrhundert. Typologie, Dramaturgie und Anthropologie einer populären Gattung, Tübingen, Niemeyer, 1998, (Studien zur deutschen Literatur 149/150)

Le BAR, ANn CATHERINE, Musical Culture and the Origins of the Enlightement in Hamburg, PhD Diss. University of Washington, 1993, pp. 63ss.

LÜTTEKEN, LAURENZ, «Metastasio im Spannungsfeld der deutschsprachigen Opernkritik des 18. Jahrhunderts», Metastasio im Deutschland der Aufklärung. Bericht über das Symposium Potsdam 1999, Eds. Laurenz Lütteken y Gerhard Splitt, Tübingen, Niemeyer, 2002, pp. 141-155. (Wolfenbütteler Studien zur Aufklärung, 28).

LÜTteKEn, LaURENZ, «Poesie als Klang: Johann Friedrich von Uffenbachs GottschedReplik und Telemanns Opernschaffen», Telemann in Frankfurt. Bericht über das Symposium. Frankfurt am Main, 26.-27. April 1996, ed. Peter Cahn, Mainz et al., Schott, 2000, pp. 248-259.

MaRX, HANS-JOACHIM y SCHRÖDER, DOROTHEA, Die Hamburger Gänsemarkt-Oper: Katalog der Textbücher (1678 - 1748), Laaber, Laaber, 1995.

Mattheson, Johann, Grundlage einer Ehrenpforte, Hamburgo 1740, edición facismilar Max Schneider, Kassel et al., Bärenreiter, 1969.

MatTHESOn, Johann, Das Neu-Eröffnete Orchestre, oder Universelle und gründliche Anleitung Wie ein Galant Homme einen vollkommenen Begriff von der Hoheit und Würde der edlen Music erlangen, seinen Gout darnach formiere / die Terminos technicos verstehen und geschicklich von dieser vortrefflichen Wissenschaft raisonnieren möge, Hamburgo 1713, edición facsimilar, Laaber, Laaber, 2004.

Mattheson, Johann, Die neueste Untersuchung der Singspiele, Hamburgo, s.n., 1744, edición facsimilar, Kassel, Bärenreiter, 1975.

MatTHESON, JohanN, «Schrifft von der musikalischen Gelehrsamkeit», Musikalische Bibliothek, ed. Lorenz Mizler, vol. 1, 3a parte, pp. 6-16. 
Mercure Galante, revista mensual, ed. Jean Donneau de Visé, París 1672-1683.

MizLER, LoREnz, Musikalische Bibliothek. [ $2^{\circ}$ y $3^{\text {er }}$ Volumen: Neu Eröffnete Musikalische Bibliothek] Oder gründliche Nachricht nebst unparteheyischem Urtheil von alten und neuen musikalischen Schriften und Büchern. 4 vols., Leipzig, 1, [1736-1738] 1739; 2, [1740-1743] 1743; 3, [1746-1752] 1752; 4, 1754, edición facimilar, Hilversum, Knuf, 1966.

NeStola, BARBARA, «La musica italiana nel «Mercure galant〉(1677-1683)», Recercare, 14, 2002, pp. 99-157.

Niedermüller, Peter, Die Oper im Lichte von Schopenhauers Musikästhetik, Tesina, Würzburg 1994.

PARAdA, ARTURo, «La recepción del Quijote en los siglos XVII y XVIII en tierras Alemanas, ¿ 〈bien〉 o 〈herramienta〉?», Anales Cervantinos, 36, 2004, pp. 345-356.

Parada, ARturo, Offene literarische Welten gegen geschlossene Denkmodelle und Sozialsysteme: Don Quijote und Anton Reiser. Frankfurt, Veurvert, 1997.

Quellentexte zur Konzeption der europäischen Oper im 17. Jahrhundert, ed. Heinz Becker, Kassel et al., Bärenreiter, 1981.

RATHJE, JÜRGEN, «Zur hamburgischen Gelehrtenrepublik im Zeitalter Matthesons», New Mattheson Studies, ed. George J. Buelow y Hans-Joachim Marx, Cambridge, Cambridge University Press, 1983, pp. 101-122.

SAINT-EvREMOND, CHARLES DE, A voice from exile : newly discovered letters to Madame de Gouville and the Abbé de Hautefeuille, (1697-1701), ed. Denys Potts. Oxford, Legenda, 2002.

Saint-Evremond, Charles de, Euvres Meslées, vol. 2, Londres, 1705, edicion facsimilar comentada, ed. Robert Finch y Eugène Joliat, Ginebra, Droz, 1979. (Textes Littéraires Français).

Saint-Evremond, Charles DE, «Die Opern, Ein Lustspiel von fünf Aufzügen», traducido por Johann Christoph Gottsched y una amiga anónima, Die Deutsche Schaubühne, vol. 2, Leipzig 1742, pp. 77-162.

SAint-EvRemond, Charles DE, Sur la tragédie ancienne et moderne, Londres, 1677.

Scheibe, Johann AdolPh, Critischer Musicus, publicación periódica, 1737-1740. Neue vermehrte und verbesserte Auflage, Leipzig 1745, edición facsimilar, Hildesheim, Olms, 1970.

SCHMIDT, CARL B., The livrets of Jean-Baptiste Lully's tragédies lyriques: a catalogue raisonné, New York, Performers Ed., 1995.

SCHNEIDER, HERBERT, Chronologisch-thematisches Verzeichnis sämtlicher Werke von JeanBaptiste Lully, Tutzing, Hans Schneider, 1981, (Mainzer Studien zur Musikwissenschaft, vol. 14).

SCHOPEnhaUer, Arthur, Die Welt als Wille und Vorstellung (1819, 1844). En: Sämtliche Werke, ed. Arthur Hübscher, vol. II y III, Wiesbaden, Brockhaus, 1948-1950.

Schriften und Briefe des Herrn von Saint Evremond und die Memoiren der Herzogin von Mazarin, ed. Karl Federn, Múnich, Georg Müller, 1912.

Seidel, Wilhelm, «Saint-Evremond und der Streit um die Oper in Deutschland», Aufklärungen. Studien zur deutsch-französischen Musikgeschichte im 18. Jahrhundert - Einflüsse und Wirkungen, vol. 2, ed. Wolfgang Birtel y Christoph-Hellmut Mahling, Heidelberg, Winter, 1986, pp. 46-54.

Textes sur Lully et l'opera français, Charles Perrault, Charles de Saint-Evremond, A.L. Le Brun, Reproducción de las ediciones: Paris 1674, 1684 y 1712, ed. François Lesure, Ginebra, Minkoff, 1987.

UfFENBACH, FRIEDRICH VON, «Von der Würde derer Singegedichte oder Vertheidigung der Opern», Musikalische Bibliothek, ed. Lorenz Mizler, 3르 vol. 3a parte, 1752, pp. 377-408. 
Wolff, Hellmuth Christian, «Die Komödie Les Opera (1677) des Saint-Evremond und ihre deutsche Fassung von Gottsched (1741)», Festschrift Heinz Becker zum 60. Geburtstag am 26. Juni 1982, ed. Jürgen Schläder y Reinhold Quandt. Laaber, Laaber, 1982, pp. 26-37.

\title{
Resumen:
}

El proceso de adaptación de la ópera, el género musical más complejo y opulento de los siglos XVII y XVIII, al escenario germánico estuvo flanqueado por una intensa y encarnizada discusión estética e ideológica. Filósofos, teólogos, críticos literarios y musicales y músicos alimentaron la disputa con argumentos de muy diverso cariz que van desde la desautorización moral por parte del protestantismo hasta la glorificación estética y están motivados no sólo por la calidad y esencia musical sino también por el impacto que la ópera tuvo en amplios sectores de la sociedad. La figura de Don Quijote tiene en este contexto una doble función: por una parte inspiró una cantidad importante de composiciones, por otra parte constituyó uno de los vínculos más fructíferos entre el discurso literario y musical.

Palabras clave: ópera, "Singspiel", siglo XVIII, estética musical, Johann Christoph Gottsched, Johann Adolph Scheibe, Lorenz Mizler, Charles de Saint-Evremond

\begin{abstract}
The process by which opera, the most complex and conspicuous musical genre of the 17th and 18th century, was adapted to the German stage triggered an intense and ardent aesthetic and ideological discussion. Philosophers, theologians, musical and literary critics and musicians contributed to this discussion with a variety of arguments that range from the moral condemnation by protestantism to the aesthetic glorification. The reasons for this critical activity are to be found not only in the musical quality and essence of opera but in the impact the genre had on broad sectors of society. The character of Don Quijote had two different functions in this context: he inspired an important amount of compositions, and he constituted a powerful link to connect the literary and the musical discourse.
\end{abstract}

Key words: opera, "Singspiel", 18th Century, music aesthetic, Gottsched, Johann Christoph, Johann Adolph Scheibe, Lorenz Mizler, Charles de Saint-Evremond. 